\title{
Os ditos e escritos acerca das formações estéticas de professores(as): um olhar para as pesquisas acadêmicas ${ }^{1}$
}

\author{
Fabiana Souto Lima Vidal \\ Clarissa Martins de Araújo \\ Universidade Federal de Pernambuco
}

\section{Resumo}

A partir da aproximação com os debates contemporâneos acerca das culturas, estéticas e arte numa visão ampliada, elaboramos o presente artigo que é fruto de uma investigação desenvolvida com o interesse de compreender o debate sobre as formações estéticas de professores(as). Recorremos ao Portal de Periódicos da Coordenação de Aperfeiçoamento de Pessoal de Nível Superior (CAPES) para buscar as investigações realizadas entre os anos de 2000 a 2011 nos níveis de Mestrado e Doutorado. O estudo trouxe aporte para entender alguns ditos e escritos acerca das formações estéticas de professores(as) nas pesquisas destacadas e também nos faz perceber a importância de estudos que propiciem pensar as formações estéticas na formação inicial em Pedagogia de diferentes lugares, contextos, realidades.

Palavras-chave: Formações Estéticas; Estado da Arte; Formação de Professores(as).

\section{Resumé}

À partir de l'approche des débats contemporains sur les cultures, esthétique et l'art d'une manière plus large, nous avons preparé cet article qui est le résultat d'une recherche développée avec l'intérêt de comprendre le débat sur les formations esthétiques des enseignants. Nous cherchons au Portal de Periódicos de la "Coordenação de Aperfeiçoamento de Pessoal de Nível Superior (CAPES)” pour rechercher les études réalisées entre les années 2000-2011 au niveaux de Master et Doctorat. Létude contribue à com-

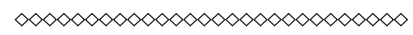

1 Uma versão inicial deste artigo foi apresentada em forma de comunicação oral durante o XXIV Congresso Nacional da Federação de Arte/Educadores do Brasil, realizado em 2014, na cidade Ponta Grossa - PR. 
prendre certaines pensées sur les formations esthétiques des enseignants et aussi reconnaître l'importance des études que nous aident à réfléchir sur les formations esthétiques dans la formation en Pédagogie des lieux, contextes et réalités différents.

Mots-clé: Formations Esthétiques; État des Connaissances; Formation des Enseignants.

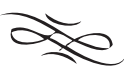

\section{As formações estéticas na/para a formação de professores(as) em Pe- dagogia: entre o debate legal e as contribuições de estudiosos(as)}

No presente artigo, partimos da compreensão de que a formação de professores(as) numa perspectiva contemporânea rompe com modelos herméticos e busca a construção de outro tipo de racionalidade. Nessa direção, as formações estéticas tornam-se elementos importantes, uma vez que trazem contributos para pensar a formação de professores(as) para além da aquisição dos saberes específicos e dos modelos que historicamente hierarquizam os campos de conhecimentos.

Isso nos leva a afirmar que compreendemos que as formações estéticas na perspectiva contemporânea de formação vão além da relação estreita com campo da arte e com as linguagens e elementos tidos eruditos que comumente circulam nos espaços institucionalizados, uma vez que alinham-se com a perspectiva expandida de culturas trazida pelos debates contemporâneos.

Esses pressupostos nos levaram a buscar os ditos e escritos acerca das formações estéticas, objeto de interesse em nossas pesquisas recentes, a fim de desenhar conexões e redes de saberes, uma vez que entendemos a importância de buscar os estudos e pesquisas realizadas e delas extrair elementos que podem dar continuidade e avançar nos debates e reflexões do campo no qual estamos inseridos(as).

Paraíso (2012, p. 35, grifos da autora) traz contribuições quando destaca que a "leitura dos 'ditos e escritos" é importante para "montar, desmontar e remontar o já dito", tendo em vista que as múltiplas leituras permitem "conhecer, mapear, mostrar o que já foi dito, pesquisado, significado, escrito, publicado, divulgado, sobre o objeto que escolhemos para investigar".

Nesse exercício de busca dos ditos e escritos fizemos um esforço para "juntar aquilo e aqueles/as que podem ser considerados comuns, semelhantes, parecidos - e separar - aquilo e aqueles/as que afirmam coisas diferentes, distintas, contrárias, conflitantes", para montagem de um mapa e a criação de uma teia de significados com os quais estabelecemos relações de aproximação e/ou distanciamentos (PARAÍSO, 2012, p. 35). Desse modo, temos a compreensão que as reflexões geradas nesse estudo constituem-se, portanto, uma primeira análise que nos permite compor, decompor, recompor, desenhar 
nossa escrita e clarear os percursos e reflexões a serem seguidas.

Na busca desses ditos e escritos, também destacamos que alguns(mas) autores(as) optam pela expressão "formação cultural", e ainda, "educação estética", para tratar especificamente do interesse do nosso estudo, as formações estéticas. Em nossas reflexões, entendemos que isto provém, sobretudo, do próprio espaçotempo ${ }^{2}$ em que as pesquisas foram realizadas, de forma sincrônica com o período em que os debates relacionados as culturas começaram a adentrar no campo educacional com maior intensidade e estarem, portanto, em processo de construção, não delineando e/ou demarcando espaços e nomenclaturas, mas já apontando para a amplitude das questões imbricadas, seja pela evolução dos debates e/ou pelas afiliações teóricas com os quais os(as) pesquisadores(as) se debruçam.

Assim, nossa investigação começa a tomar corpo ao buscarmos as pesquisas realizadas em programas de pós-graduação e disponíveis para consulta no Portal de Periódicos da Coordenação de Aperfeiçoamento de Pessoal de Nível Superior (CAPES) que tangenciam ou que tem as formações estéticas de professores(as) como eixo central.

Hoje, as discussões acerca da formação cultural são mais amplas, sobretudo a partir dos debates contemporâneos que trazem no seu bojo as reflexões acerca das culturas. Desse modo, firmamos nossa compreensão de que as formações estéticas podem ser entendidas como elementos das formações culturais, portanto, imprescindíveis para a formação de professores(as).

Para nossas construções teóricas faz-se necessário destacar a relação historicamente de negação, silenciamento e da forma como a Arte/Educação vem sendo tratada na educação brasileira, apresentando-se ainda nos dias atuais como campo de conhecimento de menor importância em grande parte das escolas e cursos de formação de professores(as), seja na formação inicial em Pedagogia, campo do nosso estudo, ou até mesmo nas formações continuadas.

Também não podemos perder de vista o que dizem Gatti, Barreto e André (2011) que corroboram nossas reflexões quando ao analisarem as políticas educativas referentes à formação inicial e continuada de professores(as), tecem uma crítica a hierarquia das disciplinas e destacam que até mesmo os projetos de formação continuada ainda continuam contemplando as áreas do conhecimento tidas historicamente como mais relevantes. Isso implica afirmar que ainda são restritas as formações continuadas que privilegiam o campo da arte, além disso, as políticas públicas estão mais preocupadas com os campos de conhecimento que integram as avaliações padronizadas. Sobre esse aspecto, o estudo de Cruz (2012) além de tecer crítica sobre a ênfase dada aos conhecimentos da língua portuguesa e da matemática, revela, pela fala dos sujeitos participantes de sua pesquisa, que são escassas as formações no campo da Arte/Educação, campo

$\infty<\infty<\infty<\infty<\infty<\infty \times \infty \times \infty \times \infty \times \infty<\infty$

2 Tomamos Macedo (2012) como referência para escrever os termos espaço e tempo unidos, para, assim como o estudioso tentar minimizar e superar nossa formação positivista e a visão dicotomizada com as quais somos (forma)dos(as) para aprender e analisar o mundo. 
este que entendemos como espaço que, prioritariamente trata das formações estéticas de professores(as).

Um dos rebatimentos da supressão da Arte/Educação na formação dos sujeitos pode ser percebido no debate travado por Aguiar (2010, p. 13, grifos da autora) quando discute em seu estudo que os(as) professores(as) da formação inicial tiveram pouco, nenhum ou superficiais contatos com a arte em sua formação, o que traz rebatimentos para sua prática e para a própria formação estética desses sujeitos.

Diante disso, podemos afirmar que desde os primeiros anos de escolarização, as experiências formativas, na maioria das vezes, não propiciam uma relação estreita, intensa ou que valide e valorize o campo da Arte/Educação. Assim, ao chegar à vida adulta, grande parte dos(as) futuros(as) professores(as) não criaram o habitus, no sentido bourdieusiano, de perceber as formações estéticas como fundantes para seu próprio processo formativo, pessoal e profissional, para suas ações e para ampliar a visão crítica do mundo, isso nos leva a suspeitar que resta à formação inicial de professores(as) essa dívida. Oliveira intensifica essa análise quando afirma:

Como a realidade do professor no ensino básico, na sua maioria, liga-se em sua origem à classe trabalhadora, muitos deles não tiveram ou não têm acesso aos bens culturais. Impõe-se assim, à instituição de ensino superior dotar cursos de condições de modo a favorecer tal contato com livros, revistas, filmes, produções culturais e os mais diversos espetáculos, exposições e manifestações populares (OLIVEIRA, 2008, p. 102).

Ao buscar compreender essas questões, tomamos como primeiro movimento a leitura do estado da arte realizado pelas pesquisadoras Bernadete Gatti, Elba Barreto e Marli André, intitulado "Políticas Docentes no Brasil: um estado da arte" e publicado em 2011, quando apresentam um mapeamento que nos permite entender elementos, lacunas e avanços da/na formação de professores(as), além de ampliar nossa compreensão acerca do estado da formação de professores(as) em âmbito nacional, sem perder de vista outros contextos da América Latina e Europa.

No âmbito legal, temos as Diretrizes Curriculares Nacionais para os cursos de Pedagogia (DCN/Pedagogia) que trazem orientações para a formação inicial. Em sintonia com este debate, as autoras estudadas contribuem para a reflexão sobre o campo da formação quando afirmam:

Quanto aos cursos de graduação em pedagogia, somente em 2006, depois de muitos debates, o CNE provou a Resolução CNE/CP n ${ }^{\circ}$ $1 / 2006$, com as Diretrizes Curriculares Nacionais para esses cursos, propondo-os como licenciatura e atribuindo a eles a responsabili- 
dade pela formação de professores para a educação infantil e anos iniciais do ensino fundamental (GATTI, BARRETO, ANDRÉ, 2011, p. 98).

Tomamos esse documento oficial para aprofundar nossas reflexões acerca da Arte/ Educação na formação de pedagogos(as), uma vez que este campo é contemplado como campo de conhecimento necessário à formação desse(a) profissional. De forma mais específica, este documento nos indica também que esta formação terá subsídios que lhe ampare para uma prática pedagógica que contemple as questões estéticas e o campo da Arte/Educação, num diálogo constante com os demais campos de conhecimentos presentes em suas práticas. Desse modo, somos levadas a entender, a importância da(s) disciplina(s) relacionada ao campo da Arte/Educação e a presença de experiências estéticas/culturais enquanto elementos da formação nos cursos de Pedagogia enquanto elementos estruturantes dessa formação (BRASIL, 2006).

Perissé (2009, p. 39) reforça nossos argumentos quando diz que "os professores todos, independente da disciplina que se preparam para ministrar, ganhariam (e com eles, seus alunos) com uma autoeducação que desse especial atenção à dimensão estética da cultura e da vida".

No contexto local, destaco a pesquisa "A construção da profissionalidade polivalente na docência nos anos iniciais do ensino fundamental: sentidos atribuídos às práticas por professoras da Rede Municipal de Ensino do Recife", de autoria de Shirleide Pereira da Silva Cruz. Esse estudo, defendido em 2012, teve como foco a docência nos anos iniciais do ensino fundamental e a construção da polivalência, entendida como organização curricular de atuação do docente dos anos iniciais do Ensino Fundamental e elemento constituinte da profissionalidade docente do(a) profissional que atua nessa etapa de escolarização (CRUZ, 2012).

Dentre as reflexões apresentadas, a referida tese despertou interesse por tratar questões relacionadas ao campo da Arte/Educação. Mais especificamente, a tese aponta uma questão crucial que ilustra parte das realidades escolares quando revela as inquietações das professoras atuantes em escolas da cidade do Recife com relação ao campo da Arte/Educação, este enquanto campo de conhecimento com o qual atuam ou deveriam atuar, mesmo não tendo formação específica, e em alguns casos, não terem sequer vivenciado este campo na formação inicial, problema este acarretado, sobretudo, pela falta de professores(as) com formação específica nesse campo em muitas escolas da Educação Básica, ficando então a cargo das professoras pedagogas, essa responsabilidade, como é o caso das participantes da referida tese. Isso fica claro no trecho de fala retirado do estudo de Cruz (2012, p. 162) e destacado abaixo:

PR: Além disso, a gente vê uma carência muito grande até nessa formação da universidade, na formação continuada. Quantas vezes 
com 25 anos de rede foi me dada uma formação de Geografia? História? Ciências?

PQ: É verdade, focam muito a questão do letramento.

PR: Língua Portuguesa e Matemática ainda são áreas privilegiadas. História e Geografia nem pensar! Não existe. Artes... passa bem distante. Você tem que trabalhar com os meninos Artes, está lá na proposta. Eu não tenho que saber Artes, eu não fui para universidade estudar Artes. Se eu tivesse ido ainda não saberia tudo...

(PR, Magistério e Pedagogia, pós-graduada, 25 anos de magistério, RPA 03 e PQ, Magistério, cursando Pedagogia, 08 anos de magistério, RPA 3).

Dando continuidade, ainda vimos que o estado da arte realizado por Gatti, Barreto e André (2011) aponta elementos importantes para nossas reflexões, quando diz:

Há uma coincidência, que acaba em redundância, que se refere à condição sociocultural dos professores e às condições de vida dos alunos das redes públicas de ensino, que, muitas vezes, apresentam alguma desvantagem social. Atualmente, no Brasil, os próprios professores são provenientes de camadas sociais menos favorecidas, com menor favorecimento educacional, especialmente os que lecionam na educação infantil e nos primeiros anos do ensino fundamental, justamente no período de alfabetização (GATTI, BARRETO, ANDRÉ, 2011, p. 28).

Essa afirmação nos levou a pensar na teia de relações ou a ausência delas, entre as formações estéticas de professores(as) e as condições sociais dos(as) mesmos(as), uma vez que as condições sociais e a educação básica pública, de onde advém grande parte do professorado, muitas vezes não oferece oportunidades de ampliar essa formação para além das referências que circundam esse sujeito, então, resta à formação superior suprir a lacuna deixada pela educação básica. Por um lado, isso implica inflar um currículo que a cada dia está mais sobrecarregado, acrescentando disciplinas relacionadas a esse campo e a tantos outros que são necessários à formação do(a) pedagogo(a). Mas isso de fato acontece? De que forma? Que alternativas são possíveis e/ou realizadas? Como isso vem acontecendo?

Vidal (2011) aponta dois caminhos que levaram a inserção de pelo menos uma disciplina relacionada à Arte/Educação integrar o currículo de parte dos cursos de Pedagogia: o crescimento desse próprio campo pelas lutas políticas e históricas que vem travando, e os interesses políticos de definir o campo de atuação dos profissionais com formação em Pedagogia, evidenciado pela inserção do campo da Arte/Educação no tex- 
to das DCN/Pedagogia.

No entanto, é preciso um olhar criterioso, pois quando insere na formação inicial em Pedagogia, pelo menos uma disciplina relacionada à Arte/Educação, por meio das DCN/Pedagogia, essa política pública está afirmando legalmente que o(a) profissional com formação nessa área está habilitado(a) a trabalhar com a arte na Educação Básica, desde a Educação Infantil aos anos iniciais do Ensino Fundamental.

Sobre isso, esse mesmo estudo revela que apenas essa inserção não tem dado conta de formar o(a) professor(a) para atuar com o campo da Arte/Educação na escola, pois, de um modo geral, apenas uma disciplina durante toda a formação, com carga horária de 60 horas, não dá elementos de fato para este(a) professor(a) para atuar com os conhecimentos práticos e teóricos em arte. Além do mais, não podemos desconsiderar as especificidades das linguagens artísticas - Artes Visuais, Dança, Música e Teatro - cada uma com campo, metodologias e formas de abordagens, leituras e vivências específicas. De um modo geral, as especificidades das linguagens não são contempladas na formação inicial em Pedagogia ou são tratadas de modo superficial.

Diante do exposto, inferimos no estudo realizado que, em grande medida, a formação inicial apenas tem dado indicativos e, ainda de forma incipiente e, muitas vezes, equivocada, transformando a fundamentação teórica deste campo em fórmulas rasteiras para se experimentar na prática, distanciando mais uma vez os(as) futuros(as) docentes de uma formação para uma práxis significativa, muitas vezes, minando ou prejudicando a formação de crianças na Educação Básica quando se trata do campo da arte.

Mais uma vez nos voltamos para o estudo realizado por Gatti, Barreto e André (2011) quando discutem a formação inicial como merecedora de atenção especial, tendo em vista que é o primeiro ponto de acesso da formação de professores(as) e por esta ter um papel fundamental na qualidade da formação docente.

Mesmo considerando a profundidade do estado da arte realizado, percebemos que as autoras não tecem considerações sobre as formações estéticas de professores(as), isto nos leva a entender que ainda se faz necessário direcionar o olhar para esse elemento da formação e nos instiga a (COM)(PAR)trilhar e buscar outros caminhos, na tentativa de encontrar esse debate em outras pesquisas realizadas.

\section{As formações estéticas nos estudos acadêmicos: um olhar para o banco de teses e dissertações da CAPES}

Partimos das inquietações apresentadas anteriormente e começamos a buscar os ditos e escritos em pesquisas já realizadas. Desse modo, recorremos ao Banco de Teses e Dissertações da Coordenação de Aperfeiçoamento de Pessoal de Nível Superior (CAPES) e buscamos as investigações realizadas e defendidas entre os anos de 2000 a 2011 que tem como eixo as formações estéticas de professores(as). 
A partir do exposto, estabelecemos os seguintes critérios para refinar nossa busca: utilizar no campo assunto as expressões exatas "Formação Estética" e "Estética Formação"; selecionar os estudos nos níveis: Doutorado e Mestrado; utilizar como ano base: de 2000 a 2011; realizar a leitura de títulos e resumos; direcionar o olhar para as pesquisas que estão no entrelaçamento da formação/educação estética e/ou formação cultural na formação de professores(as), lançando um olhar mais incisivo para os estudos que tiveram a formação inicial nos cursos de Pedagogia como campo; leitura na íntegra dos estudos selecionados; identificação dos temas abordados e apontamentos revelados pelos(as) pesquisadores(as).

Uma vez que entendemos que uma palavra apenas não é suficiente para rastrear os estudos que convergem para o nosso tema de interesse, ressaltamos que foi preciso a construção de um olhar caleidoscópico, para entender o emaranhado de elementos que podem constituir uma pesquisa. Desse modo, num primeiro momento, nos utilizamos das expressões "formação estética" e, em seguida, utilizamos a expressão "estética formação", para dar amplitude a nossa busca e percebemos que, o fato de inverter as palavras já nos reporta a diferentes estudos, conforme discutiremos a seguir.

Os primeiros achados nos revela um total de 26 pesquisas encontradas a partir da primeira expressão pesquisada - Formação Estética - destas, 7 teses e 19 dissertações. No entanto, ao adentrarmos na leitura dos referidos estudos e ao direcionarmos nosso olhar para os que aproximam as formações estéticas da formação inicial em Pedagogia concluímos que, apenas 2 pesquisas convergem para nosso interesse de pesquisa. Já na pesquisa que tomou a expressão "Estética Formação", encontramos um total de 25 pesquisas, destas 4 teses e 21 dissertações, no entanto, apenas 3 estudos se aproximam do nosso interesse de pesquisa, destes, 1 estudo repete-se na pesquisa com a expressão anterior.

Ao final dessa investigação é possível afirmar que, entre 2000 e 2011 apenas 4 pesquisas realizadas se aproximam do nosso interesse de estudo, a aproximação entre as formações estéticas de professores(as) e a formação inicial nos cursos de Pedagogia.

Após essa análise inicial, passamos a desconfiar que as formações estéticas pudessem ser abordadas em estudos que tivessem como tema central a "formação cultural" de professores(as), então, tomando essa expressão como norteadora, passamos a buscar no mesmo ano base, as pesquisas, nos níveis Mestrado e Doutorado, que tratam das formações estéticas mas, que utilizam-se da expressão "formação cultural".

Esta investigação nos revelou um total de 215 pesquisas, destas, 47 teses e 168 dissertações. No entanto, ao adentrar na leitura dos títulos e resumos, percebemos que apenas 3 estudos aproximam-se do nosso interesse de pesquisa.

Por fim, realizamos uma nova busca de teses e dissertações a partir da expressão "educação estética" quando encontramos apenas um estudo realizado no nível de Mestrado e defendido em 2012, trata-se da pesquisa realizada por Simone Maria Scartazzini.

Diante do exposto podemos afirmar que em 12 anos de pesquisas, de 2000 a 2011, no Banco de Teses e Dissertações da CAPES encontramos, a partir dos critérios e ex- 
pressões de escolha por nós estabelecidos, um total de 267 estudos, sendo 58 teses e 209 dissertações. No entanto, com o refinamento da pesquisa a partir dos demais critérios elencados, chegamos a um total de 8 estudos que se aproximam do tema do nosso interesse, sendo, 4 teses e 4 dissertações.

\section{Adentrando nas investigações}

A leitura na íntegra dos estudos que se aproximam do nosso interesse de investigação nos permite afirmar que todas as teses foram defendidas junto a Programas de Pós-Graduação em Educação (PPGE), destas, 3 foram realizadas na região Sudeste, mais especificamente, Universidade Federal do Espírito Santo (UFES), Universidade de São Paulo (USP) e Universidade Estadual Paulista Júlio de Mesquita Filho (UNESP), e apenas 1 tese defendida na região Nordeste, na Universidade Federal do Ceará (UFC).

Ressaltamos que não tivemos acesso à pesquisa na íntegra realizada por Carvalho (2003) e intitulada "Formação cultural de professores de séries iniciais e suas implicações no ensino da arte”. Nosso contato com esta investigação deu-se pela leitura do texto apresentado pela pesquisadora durante o "Seminário Estadual: O Ensino da Arte: A Prática de Ensino", realizado no Polo Arte na Escola, da Universidade Federal do Maranhão (UFMA), de 12 a 16/12/2005, e disponível em endereço eletrônico.

Quanto às dissertações, todas realizadas no campo da Educação, sendo 3 delas defendidas na região Sudeste, Universidade da Cidade de São Paulo (UNICID), Pontifícia Universidade Católica de Campinas (PUC-Campinas) e Universidade de Passo Fundo (UPF), em Minas Gerais e apenas uma pesquisa realizada na região Sul, pela Universidade do Vale do Itajaí (UNIVALI-SC). Logo, os critérios estabelecidos nos revelam que, na região Nordeste não encontramos nenhuma dissertação que tem como foco de estudo as formações estéticas de professores(as).

Ao adentrar nos estudos supracitados, podemos afirmar que Aguiar (2010) em sua pesquisa, parte de sua prática, enquanto professora de Artes e passa a questionar a formação estética de futuros(as) docentes, estudantes de cursos de Pedagogia. Parte desses elementos iniciais para analisar o processo de constituição do sentido estético de estudantes do curso de Pedagogia, noturno, de uma faculdade privada na região da grande Vitória - ES, tomando como objeto do estudo, a disciplina na qual é professora. A partir da análise realizada, tece considerações acerca do desenvolvimento do sentido estético como algo que vai além do campo da arte, e que, especificamente na formação de professores(as), a Arte/Educação traz contributos que podem ampliar as formas dos sujeitos de pensar, sentir, criticar e ver o mundo, conforme podemos perceber no fragmento abaixo:

O desenvolvimento do sentido estético é também objeto do ensi- 
no de Arte na medida em que esse trabalha com ações, atividades, materiais e recursos que possibilitam ao sujeito aprimorar seus sentidos de modo a perceber de forma mais sensível, não somente a Arte como as coisas que o rodeiam. Para tanto o ensino de Arte deve oportunizar experiências estéticas significativas (AGUIAR, 2010, p. 178).

Oliveira (2008) em seu estudo, único da região Nordeste, também defende a mesma ideia de que as vivências com a arte, com o universo artístico local, nacional e global são contributos para uma formação mais ampla e crítica de professores(as). Sua pesquisa direciona-se para o espaço da dimensão estética no currículo da formação docente, no entanto, sobre a formação superior, é importante destacar que a autora escreve num período em que os cursos de Pedagogia do Brasil, e o campo no qual se insere, a UFC, começaram a passar por reformas curriculares para agregar as orientações advindas das DCN/Pedagogia, hoje, certamente este estudo apontaria para outras direções.

Por sua vez, o estudo realizado por Nogueira (2002) tem como ponto de partida as vivências da pesquisadora, quando passa a perceber dois tipos de profissionais, professores(as) com experiências estéticas e culturais restritas e os profissionais com alguma experiência. Já ao atuar na formação de professores(as), Nogueira começou a perceber que a maioria dos(as) estudantes possuíam experiências culturais restritas e passou a buscar em sua pesquisa a relação entre a formação cultural e a prática docente na formação de professores(as), a partir de dois cursos de Pedagogia investigados.

Vale destacar que, mesmo considerando as críticas recebidas, a pesquisadora revela que em seu estudo faz opção de enfatizar a cultura historicamente conhecida, tratada pela autora como "patrimônio que a humanidade construiu há séculos", tomando-a como referência para tratar a formação cultural.

Destacamos que, assim como Aguiar (2010) e Carvalho (2003), também nos diferimos do posicionamento da pesquisadora supracitada, que defende que as experiências estéticas se dão exclusivamente pela arte, sobretudo por defendermos arte e estética a partir de uma visão ampliada, horizontal na formação de professores(as). Assim como nós, Aguiar considera "a possibilidade de que o sujeito passe por experiências estéticas em diferentes espaçostempos de sua vida estando ele em contato com a Arte ou não" (AGUIAR, 2010, p. 48). Também com esse olhar ampliado para os lugares e formas de uma aproximação com as formações estéticas, Carvalho (2003) afirma que nossas formas de ensinar e aprender recebem influência de várias culturas - erudita, popular, tradicional, indústria cultural - logo, aponta para a necessidade de contemplar as manifestações advindas dessas culturas no campo educacional, seja no cotidiano escolar ou nos cursos de formação de professores(as).

A pesquisa realizada por Carvalho (2003) teve como objetivo investigar o modo como o currículo aborda a formação cultural de professores(as) de séries iniciais e sua influência no ensino da arte, na escola. Assim como os demais estudos de tese destaca- 
dos, esta autora também afirma que boa parte dos(as) professores(as), e inclusive dos(as) estudantes dos cursos de Pedagogia, estão distantes ou despreparados para uma formação e uma familiarização estética e epistemológica com o campo da Arte/Educação, mais precisamente, o olhar da pesquisadora converge para o Ensino das Artes Visuais e para os professores(as) pedagogos(as) que atuam com esse campo nos anos iniciais da Educação Básica. Em suas análises, destaca que para uma prática no campo da arte os "professores de séries iniciais precisam ter re-significada sua formação cultural por meio do resgate, problematização e compreensão das manifestações das linguagens artísticas em suas trajetórias de vida, tanto na sua formação acadêmica inicial quanto permanente" (CARVALHO, 2003, p. 2).

Começamos nossas reflexões a partir das dissertações encontradas tomando o estudo de Soares (2008) como ponto de partida. Assim como nós, a pesquisadora entende que a educação estética desempenha papel fundamental na formação de professores(as), posição esta também defendida por Scartazzini (2012), para elas a educação estética é parte constitutiva do ser humano integral. Partindo desse pressuposto, a primeira pesquisadora desenvolveu o seu estudo a partir de grupo de 11 professoras participantes de uma formação docente, enquanto que a segunda desenvolveu oficinas de educação estética para realizar o seu estudo de caso com 4 professoras e 7 monitoras atuantes nos anos iniciais da Educação Básica. Em sua análise, apoiando-se no método indiciário Soares (2008) conclui que, ao abranger o repertório cultural pelo contato com as manifestações artísticas, as professoras passaram a assumir uma postura de maior curiosidade e observação do próprio entorno, não apenas das questões visuais, mas de outras habilidades. Já Scartazzini (2012) percebeu que as oficinas vivenciadas provocou mudanças na prática das professoras participantes da pesquisa.

Por sua vez, a pesquisa realizada por Santos (2011) teve como objeto a educação estética na formação inicial de professores(as), a partir do olhar sobre o Projeto Político Pedagógico do curso de Pedagogia na modalidade à distância da Universidade de Santo Amaro (UNISA). Para o autor, a educação estética na formação de professores(as) constitui-se como importante elemento para a autonomia e emancipação dos sujeitos, para formas de intervenção e de resistência a alienação atrelada à indústria cultural, pelos processos formativos na escola e na formação superior, conforme nos expõe quando toma Freire como aporte:

Os indivíduos constroem uma cultura e são, ao mesmo tempo, construídos por ela. Trata-se da própria formação do indivíduo e de suas capacidades, conforme a concepção da teoria freireana: a formação ética e estética acontece, mais precisamente, na sala de aula, quando professores e alunos lutam por uma educação transformadora, dialógica e conscientizadora (SANTOS, 2011, p. 149). 
Essas questões são essenciais para pensar um projeto de formação de professores(as) que busque ir além da formação ancorada na aquisição de saberes específicos e necessários a prática, direcionando-se para uma formação ampla, crítica e reflexiva do sujeito, capaz de ler o mundo de diferentes formas, a partir de diferentes linguagens.

Por sua vez, Carvalho (2009) na pesquisa sobre a formação cultural dentro de um projeto de formação em serviço, faz um estudo sobre cultura, e nos leva a pensar na teia de relações que estabelecemos por meio das culturas e de como os elementos citados pelo pesquisador contribuem para/na formação de sujeitos conhecedores do global e do local, conhecedores de si e do outro.

Em sua investigação, este pesquisador tece considerações mais contundentes relacionadas à formação de professores(as) no contexto analisado, o programa Pedagogia Cidadã, mas que serve para pensarmos outros contextos e nos leva a refletir sobre uma formação ampliada, apoiada em outro paradigma de formação quando afirma que, para além do que é proposto na matriz curricular, "no que se refere à questão cultural, é preciso que se realizem vivências culturais concretas no decorrer do curso, não apenas sendo mencionadas e estudadas as expressões, manifestações e questões artístico-culturais, é preciso, também que o aluno tenha participações práticas e vivências culturais" (CARVALHO, 2009, p. 83).

\section{Para concluir: algumas considerações}

Ao final deste estudo podemos afirmar que o estado da arte realizado nas pesquisas encontradas no Banco de Teses e Dissertações da Capes nos traz aporte para entender alguns ditos e escritos acerca das formações estéticas de professores(as) nas pesquisas destacadas.

A investigação que serviu de base para o presente artigo nos faz perceber a importância de estudos que abram caminhos para pensar as formações estéticas na formação inicial em Pedagogia de diferentes lugares, contextos, realidades. Também nos faz compreender como existem aproximações entre as motivações que geraram as pesquisas, nascidas e movidas pela aproximação com o campo, com a vivência e inquietações dos sujeitos - pesquisadores(as) e professores(as) -, e de como os caminhos traçados e as escolha teóricas revelam achados que convergem para uma compreensão mais ampliada da formação de professores(as), trazendo elementos para pensar, tracejar, desenhar rotas, trilhas e percursos.

Por fim, nos valemos do fragmento do poema barroco de Gregório de Matos, quando nos diz: 
O todo sem a parte não é todo,

A parte sem o todo não é parte,

Mas se a parte o faz todo, sendo parte,

Não se diga, que é parte, sendo todo.

Esse poema nos faz entender que, o presente estudo é parte e todo, ao mesmo tempo, é um recorte delineado pelos critérios elencados e que nos dá, portanto, alguma dimensão das pesquisas que atendem aos mesmos e é todo, se considerarmos que o presente estado da arte ajusta-se num período de 11 anos de estudos, fecha, portanto, um ciclo, sem a pretensão de encerrar-se nele ou de tê-lo como verdade, é apenas um modo de ver, uma perspectiva de olhar e analisar, abrindo-se para a possibilidade de abertura para outros ciclos.

\section{Referências bibliográficas}

AGUIAR, Maira Pêgo de. A constituição do sentido estético de alunos do Curso de Pedagogia. 2010. 220 p. Tese (Doutorado em Educação) - Centro de Educação, Universidade Federal do Espírito Santo, Vitória, 2010.

BRASIL. Diretrizes Curriculares Nacionais para o Curso de Pedagogia. Brasília: MEC/SEF, 2006. Disponível em: < http://portal.mec.gov.br/cne/arquivos/pdf/rcp01_06. pdf >. Acesso em: 12 Set. 2011.

CARVALHO, Alexandre Sônego de. Formação cultural do professor no Programa Pedagogia Cidadã. 2009. 95 p. Dissertação (Mestrado em Educação) - Faculdade de Educação, Pontifícia Universidade Católica de Campinas, Campinas, 2009.

CARVALHO, S. H. E.. Formação cultural de professores de séries iniciais e suas implicações no ensino da arte. Tese (Doutorado em Educação) - Universidade Estadual Paulista Júlio de Mesquita Filho, UNESP, 2003.

CRUZ, S. P. S. A construção da profissionalidade polivalente na docência nos anos iniciais do ensino fundamental: sentidos atribuídos às práticas por professoras da rede municipal de ensino do Recife. 2012. 280 p. Tese (Doutorado) - Universidade Federal de Pernambuco, CE, Programa de Pós-Graduação em Educação, 2012.

GATTI, B. A.; BARRETO, E. S. de S; ANDRÉ, M. E. D. de A. Políticas docentes no Brasil: um estado da arte. Brasília: UNESCO, 2011.

OLIVEIRA, Edite Colares. A dimensão estética na formação do educador: a elaboração de um ideário coletivo. 2008. 207 p. Tese (Doutorado em Educação Brasileira). 
- Faculdade de Educação, Universidade Federal do Ceará, Fortaleza, 2008.

MACEDO, Roberto Sidnei. A etnopesquisa implicada: pertencimento, criação de saberes e afirmação. Brasília: Liber Livro, 2012.

MATOS, Gregório de. Obra poética. Org. James Amado. Prep. e notas Emanuel Araújo. Apres. Jorge Amado. 3.ed. Rio de Janeiro: Record, 1992.

NOGUEIRA, Monique Andries. A formação cultural de professores ou a arte da fuga. 2002. Tese (Doutorado em Educação) - Faculdade de Educação da USP, Universidade de São Paulo, USP, 2002.

PARAÍSO, M. A. Metodologias de pesquisas pós-críticas em educação e currículo: trajetórias, pressupostos, procedimentos e estratégias analíticas. In: MEYER, D. E. PARAÍSO, M. A. (orgs.). Metodologias Pós-Críticas em Educação. Belo Horizonte: Mazza Edições, 2012.

PERISSÉ, Gabriel. Estética e Educação. Belo Horizonte: Autêntica Editora, 2009.

SANTOS, A. C. B. A. Educação estética e formação inicial de professores da Educação Básica: um estudo hermenêutico do projeto político-pedagógico do curso de Pedagogia, na modalidade a distância. 2011. 190 p. Dissertação (Mestrado em Educação). Universidade Cidade de São Paulo, São Paulo, 2011.

SCARTAZZINI, Simone Maria. A educação estética na formação em serviço do professor de Educação Infantil. 2012. 114 p. Faculdade de Educação, Universidade de Passo Fundo, Passo Fundo, 2012.

SOARES, Maria Luiza Passos. Educação estética - investigando possibilidades a partir de um grupo de professoras. Dissertação (Mestrado Acadêmico em Educação). 2008. 99 p. Universidade do Vale do Itajaí, Itajaí, 2008.

VIDAL, F. S. L. A Formação Inicial de Professores e o Ensino da Arte: um estudo em Instituições do Ensino Superior do Estado de Pernambuco. 2011. 213 p. Dissertação (Mestrado em Educação) - Centro de Educação, Universidade Federal de Pernambuco, Recife, 2011. 